\title{
A Study of Thermal Stability of Hydroxyapatite
}

\author{
Natalia V. Bulina ${ }^{1, *} \mathbb{C D}^{\text {, Svetlana V. Makarova }}{ }^{1}$ (), Sergey G. Baev ${ }^{2}$, Alexander A. Matvienko ${ }^{1}$, \\ Konstantin B. Gerasimov ${ }^{1}$, Olga A. Logutenko ${ }^{1}$ and Vladimir S. Bystrov ${ }^{3}$ (D) \\ 1 Institute of Solid State Chemistry and Mechanochemistry, Siberian Branch of the Russian Academy of Sciences, \\ 630128 Novosibirsk, Russia; makarova@solid.nsc.ru (S.V.M.); matvienko67@gmail.com (A.A.M.); \\ gerasimov@solid.nsc.ru (K.B.G.); ologutenko@solid.nsc.ru (O.A.L.) \\ 2 Institute of Automation and Electrometry, Siberian Branch of Russian Academy of Sciences, \\ 630090 Novosibirsk, Russia; baev@iae.nsk.su \\ 3 Institute of Mathematical Problems of Biology, The Branch of Keldysh Institute of Applied Mathematics, \\ Russian Academy of Sciences, 142290 Pushchino, Russia; vsbys@mail.ru \\ * Correspondence: bulina@solid.nsc.ru; Tel.: +7-383-233-24-10
}

check for updates

Citation: Bulina, N.V.; Makarova, S.V.; Baev, S.G.; Matvienko, A.A.; Gerasimov, K.B.; Logutenko, O.A.; Bystrov, V.S. A Study of Thermal Stability of Hydroxyapatite. Minerals 2021, 11, 1310. https://doi.org/ $10.3390 / \min 11121310$

Academic Editors: Josy A. Osajima, Edson Cavalcanti da Silva Filho and Maria Gardennia Fonseca

Received: 20 October 2021

Accepted: 20 November 2021

Published: 24 November 2021

Publisher's Note: MDPI stays neutral with regard to jurisdictional claims in published maps and institutional affiliations.

Copyright: (c) 2021 by the authors. Licensee MDPI, Basel, Switzerland. This article is an open access article distributed under the terms and conditions of the Creative Commons Attribution (CC BY) license (https:/ / creativecommons.org/licenses/by/ $4.0 /)$.
Abstract: High-temperature powder sintering is an integral part of the dense ceramic manufacturing process. In order to find the optimal conditions for producing a ceramic product, the information about its behavior at high temperatures is required. However, the data available in the literature are very contradictory. In this work, the thermal stability of hydroxyapatite prepared by a solidstate mechanochemical method and structural changes occurring during sintering were studied. Stoichiometric hydroxyapatite was found to remain as a single-phase apatite structure with the space group $\mathrm{P}_{3} / \mathrm{m}$ up to $1300{ }^{\circ} \mathrm{C}$ inclusively. A further increase in the sintering temperature leads to its partial decomposition, a decrease in the crystallite size of the apatite phase, and the appearance of significant structural strains. It was shown that small deviations from stoichiometry in the $\mathrm{Ca} / \mathrm{P}$ ratio upward or downward during the hydroxyapatite synthesis lead to a significant decrease in the thermal stability of hydroxyapatite. An apatite containing almost no hydroxyl groups, which is close to the composition of oxyapatite, was prepared. It was shown that the congruent melting of stoichiometric hydroxyapatite upon slow heating in a high-temperature furnace does not occur. At the same time, the fast heating of hydroxyapatite by laser radiation allows, under certain conditions, its congruent melting with the formation of a recrystallized monolayer of oxyhydroxyapatite. The data obtained in this study can be used when choosing sintering conditions to produce hydroxyapatitebased ceramics.

Keywords: hydroxyapatite; oxyhydroxyapatite; oxyapatite; sintering; thermal stability; melting

\section{Introduction}

Hydroxyapatite (HA), also known as hydroxylapatite in earlier literature, is a rare, naturally occurring mineral with the chemical formula $\mathrm{Ca}_{5}\left(\mathrm{PO}_{4}\right)_{3}(\mathrm{OH})$. HA formula is commonly written as $\mathrm{Ca}_{10}\left(\mathrm{PO}_{4}\right)_{6}(\mathrm{OH})_{2}$ in order to show that the crystal unit cell comprises two entities. HA is the hydroxyl end member of the apatite group with general formula $\mathrm{M}_{10}\left(\mathrm{RO}_{4}\right)_{6} \mathrm{X}_{2}$. The hydroxyl ion in the HA structure can be replaced by fluoride, chloride, or carbonate producing fluorapatite, chlorapatite, or carbonateapatite, respectively [1]. Apart from that, the substitution of calcium cations and the tetrahedral phosphate ion in HA is also possible [2]. In the case of partial replacement of the ions, the corresponding solid solutions are formed. Replacement in the HA structure significantly changes both its structural characteristic [3,4] and physicochemical and biological properties [2].

Synthetic HA can be prepared by different methods, such as precipitation from an aqueous solution, by the sol-gel process, hydrothermal, mechanochemical, and solid-state reaction methods, among others [5-7].

HA is produced in the form of an ionic crystal, either of hexagonal $\left(P 6_{3} / m\right)$ or monoclinic $\left(P 2_{1} / b\right)$ symmetry, depending on the conditions $[1,8,9]$. The main difference between 
the hexagonal and the monoclinic HA is the orientations of the hydroxyl groups located in the channel formed by calcium cations [9]. In monoclinic HA, all of the $\mathrm{OH}$ groups in a given column are pointed in the same direction, and the direction reverses in the next column. In hexagonal $\mathrm{HA}$, the adjacent $\mathrm{OH}$ groups point in opposite directions. The most common case is crystallization of the HA with the formation of a less ordered hexagonal structure.

The values of lattice parameters for hexagonal HA reported in the literature differ (Table 1). This can be explained by the fact that to prepare a stoichiometric HA, Ca- and $\mathrm{PO}_{4}$-containing compounds should be mixed with a strict $\mathrm{Ca} / \mathrm{P}$ ratio of 1.667. However, maintaining the $\mathrm{Ca} / \mathrm{P}$ ratio of 1.667 is a difficult task, since various synthesis conditions, in particular the $\mathrm{pH}$ of the solution, significantly affect it $[1,10,11]$. Thus, if the proper $\mathrm{pH}$ is not maintained, the so-called calcium-deficient apatite or calcium-rich HA (nonstoichiometric HAs) is formed [1,11]. In addition, the carbonate ions or other impurity ions used for preparing HA can be incorporated into its structure during the precipitation process [1,12], thus affecting the values of the lattice constants [4].

Table 1. Structural parameters of the hydroxyapatite (HA) and oxyapatite (OA) reported in the literature.

\begin{tabular}{|c|c|c|c|c|c|c|c|c|}
\hline Crystal System & Space Group & $a(\AA)$ & $b(\AA)$ & $c(\AA)$ & $\alpha\left({ }^{\circ}\right)$ & $\beta\left({ }^{\circ}\right)$ & $\gamma\left({ }^{\circ}\right)$ & Reference \\
\hline \multicolumn{9}{|c|}{ HA } \\
\hline \multirow{2}{*}{ Hexagonal } & \multirow{2}{*}{$P 6_{3} / m$} & 9.4302 & 9.4302 & 6.8911 & 90 & 90 & 120 & {$[9,11]$} \\
\hline & & 9.4176 & 9.4176 & 6.8814 & 90 & 90 & 120 & [1] \\
\hline \multirow{3}{*}{ Monoclinic } & \multirow{3}{*}{$P 2_{1} / b$} & 9.4176 & $2 a$ & 6.8804 & 90 & 90 & 120 & [1] \\
\hline & & 9.4214 & $2 a$ & 6.881 & 90 & 90 & 120 & [9] \\
\hline & & 9.84214 & $2 a$ & 6.8814 & 90 & 90 & 120 & [11] \\
\hline \multicolumn{9}{|c|}{ OA } \\
\hline \multirow{2}{*}{ Hexagonal } & $P 6_{3} / m$ & 9.40 & 9.40 & 6.89 & 90 & 90 & 120 & [1] \\
\hline & $P \overline{6}$ & 9.432 & 9.432 & 6.881 & 90.3 & 90 & 119.9 & {$[3,9,11]$} \\
\hline
\end{tabular}

Due to its chemical similarity to the mineral component of human bone and dental tissue, hydroxyapatite is widely used in medicine, particularly, as filler material to repair bone defects, to produce ceramic implants or coatings on metal implants, for the preparation of bone cements, as drug delivery systems, and as an additive in toothpastes and cleaning means $[11,13,14]$. In addition, synthetic HA is used as a filler for column chromatography, as gas sensors, catalysts, and sorbents [11,15]. However, in order to achieve the required characteristics of the final product, such as density, porosity, morphology, mechanical, and electrical/dielectrical properties, heat treatment of the synthetic HA is necessary [16,17].

The thermal behavior of HA during heat treatment is affected by the composition, structure, morphology, dispersibility, and some other properties of HA, which depend on its synthesis conditions. HA samples synthesized by precipitation, hydrothermal, sol-gel, and mechanochemical methods usually contain water incorporated into its structure. The evolution of adsorbed water is observed at low temperatures. It does not affect the lattice parameters of HA [18]. Water in pores, cracks, and inter-crystallite locations is stabilized by capillary effects and requires higher temperatures for release. The removal of lattice water from HA is observed with a further increase in temperature and leads to a contraction of the lattice parameter $a$ [19]. Moreover, the surface phosphorus is reactive and readily forms the $\mathrm{P}-\mathrm{OH}$ groups which are dehydroxylated when heated to form surface P-O-P groups [20].

The process of HA dehydroxylation with the release of water starts at a noticeable rate at $850-900{ }^{\circ} \mathrm{C}$ [18] and leads to the formation of vacancies in the position of the hydroxyl groups in the HA structure. As a result, the formation of oxyhydroxyapatite (OHA) takes place by the following reaction: 


$$
\mathrm{Ca}_{10}\left(\mathrm{PO}_{4}\right)_{6}(\mathrm{OH})_{2} \rightarrow \mathrm{Ca}_{10}\left(\mathrm{PO}_{4}\right)_{6}(\mathrm{OH})_{2-2 \mathrm{x}} \mathrm{O}_{\mathrm{x}} \square_{\mathrm{x}}+\mathrm{xH}_{2} \mathrm{O}
$$

where $\square$ is the $\mathrm{OH}$-group vacancy.

The dehydroxylation process is affected by the kinetic factors, the heating rate, and the water vapor partial pressure. The slower the heating rate, the more hydroxyl groups leave the structure during heating to a certain temperature [1,21].

The limiting threshold for reaction (1) is $\mathrm{x}=1$ when the apatite structure has no hydroxyl groups and an oxyapatite $(\mathrm{OA}) \mathrm{Ca}_{10}\left(\mathrm{PO}_{4}\right)_{6} \mathrm{O}_{1} \square_{1}$ is formed. In air, $\mathrm{OA}$ is metastable. The restoration of the lost hydroxyl groups, i.e., rehydroxylation, occurs upon its cooling in an air environment. This is due to the fact that reaction (1) is reversible, so an increase in the water vapor pressure and a decrease in the temperature lead to the incorporation of water into the OA structure [22]. The concentration of the restored hydroxyl groups depends on the heating temperature, the density of the substance, and water partial pressure.

An increase in the temperature above $1300{ }^{\circ} \mathrm{C}$ leads to decomposition of the OA with the formation of $\alpha$-tricalcium and tetracalcium phosphates, and calcium oxide by the following reactions $[18,22]$ :

$$
\begin{gathered}
\mathrm{Ca}_{10}\left(\mathrm{PO}_{4}\right)_{6} \mathrm{O} \rightarrow 2 \mathrm{Ca}_{3}\left(\mathrm{PO}_{4}\right)_{2}+\mathrm{Ca} \mathrm{O}_{4}\left(\mathrm{PO}_{4}\right)_{2} \\
\mathrm{Ca}_{10}\left(\mathrm{PO}_{4}\right)_{6} \mathrm{O} \rightarrow 3 \mathrm{Ca}_{3}\left(\mathrm{PO}_{4}\right)_{2}+\mathrm{CaO} .
\end{gathered}
$$

The OA decomposition also depends on the heating rate and water partial pressure. In study [23], the dependence of the thermal stability of OA on the water vapor pressure is reported. OA decomposes in vacuum at temperatures above $1050{ }^{\circ} \mathrm{C}$. An increase in the vapor pressure up to $30 \mathrm{~mm} \mathrm{Hg}$ leads to an increase in its stability up to $1420{ }^{\circ} \mathrm{C}$.

With a further increase in temperature, incongruent melting of the material can be achieved. As reported by Riboud, incongruent melting of HA occurs at $1570{ }^{\circ} \mathrm{C}$ [24]. According to [23], congruent melting of HA does not occur at a water partial pressure of less than $100 \mathrm{~mm} \mathrm{Hg}$. However, some authors reported that congruent melting of HA occurs. Thus, Bhatnagar [25] and Ma et al. [26] report that the melting points of HA are 1614 and $1500{ }^{\circ} \mathrm{C}$ respectively. In other studies $[27,28]$, it was also shown that selective laser melting and detonation spraying allows melting of the HA powder to occur without its decomposition.

There is a huge number of studies concerning hydroxyapatite reported in the literature. However, little attention has been given to the investigation of the structure of $\mathrm{OA}$, and those that have been reported in the literature are contradictory with regard to the lattice constants (Table 1 ). Thus, the authors of review articles $[3,11]$ reported that OA has the hexagonal symmetry with space group $P \overline{6}$. Elliott reported that OA retains the structure of HA, $P 6_{3} / m$ [1]. The determination of the lattice parameters of HA during heating in vacuum at $800{ }^{\circ} \mathrm{C}$ showed that the $\mathrm{OA} a$ parameter is less, while the $\mathrm{OA} c$ parameter is higher than the corresponding values $a$ and $c$ for HA [29].

In this work, the behavior of stoichiometric HA during heating in various ways up to the melting temperature was studied. The studies were carried out using an HA powder synthesized by the soft mechanochemical method [7]. Since this synthesis method is solid state, there is no need to maintain the required $\mathrm{pH}$ of the medium, while the $\mathrm{Ca} / \mathrm{P}$ ratio in the synthesized product depends only on the mass ratios of the starting reagents, which facilitates the procedure for producing stoichiometric HA.

\section{Materials and Methods}

The HA powder was synthesized by the mechanochemical method via mechanical treatment of the reaction mixture in the planetary ball mill, AGO-2 (ISSCM SB RAS, Novosibirsk, Russia), which is equipped with two water-cooled steel vials according to the published procedure [7]. Anhydrous calcium hydrogen phosphate, $\mathrm{CaHPO}_{4}$, and just calcined calcium oxide, $\mathrm{CaO}$, were the initial components in the synthesis. All reagents 


$$
\begin{array}{ll}
\mathrm{Ca} / \mathrm{P}=1.6 & 6 \mathrm{CaHPO}_{4}+3.6 \mathrm{CaO} \rightarrow \mathrm{Ca} 9.6\left(\mathrm{HPO}_{4}\right)_{0.4}\left(\mathrm{PO}_{4}\right)_{5.6}(\mathrm{OH})_{1.6}+2 \mathrm{H}_{2} \mathrm{O} \\
\mathrm{Ca} / \mathrm{P}=1.667 & 6 \mathrm{CaHPO}_{4}+4 \mathrm{CaO} \rightarrow \mathrm{Ca}_{10}\left(\mathrm{PO}_{4}\right)_{6}(\mathrm{OH})_{2}+2 \mathrm{H}_{2} \mathrm{O} \\
\mathrm{Ca} / \mathrm{P}=1.7 & 6 \mathrm{CaHPO}_{4}+4.2 \mathrm{CaO}+0.315 \mathrm{CO}_{2} \rightarrow 1.05 \mathrm{Ca}{ }_{9.7}\left(\mathrm{PO}_{4}\right)_{5.7}\left(\mathrm{CO}_{3}\right)_{0.3}(\mathrm{OH})_{1.7}+2.11 \mathrm{H}_{2} \mathrm{O} .
\end{array}
$$

were of chemically pure grade manufactured by Vekton Company (St. Petersburg, Russia). The reagents were mixed in ratios according to the following equations:

Compacting the HA pellets with a diameter of $13 \mathrm{~mm}$ was carried out at a loading of 3 tons using a manual hydraulic press.

Sintering of the powders and pellets was carried out in a high-temperature electrical furnace, PVK-1.6-5 (Teplopribor, Ekaterinburg, Russia), with a chamber volume of $5 \mathrm{~L}$ at different temperatures $\left(1000-1500{ }^{\circ} \mathrm{C}\right)$ using a heating rate of $5{ }^{\circ} \mathrm{C} / \mathrm{min}$. Powder $(0.7 \mathrm{~g})$ was sintered in a corundum crucible; pellets $(0.7 \mathrm{~g})$ were placed on the HA plate. The material was cooled in the furnace in air atmosphere and at a cooling rate of $5{ }^{\circ} \mathrm{C} / \mathrm{min}$. The experiments were carried out at $25 \%$ humidity and at $28^{\circ} \mathrm{C}$ at room conditions.

The surface of the unsintered pellet was treated with a $\mathrm{CO}_{2}$ laser operating at a wavelength of $10.6 \mu \mathrm{m}$, using the experimental unit developed by the Institute of Automation and Electrometry SB RAS (Novosibirsk, Russia) [30]. The samples were irradiated by raster scanning of the surface with a focused laser beam in the program control mode with the following parameters: size of laser spot $-0.2 \mathrm{~mm}$, scan-line pitch $-0.05 \mathrm{~mm}$, scanning speed -500 or $200 \mathrm{~mm} / \mathrm{s}$, and laser power $-4 \mathrm{~W}$. During the experiments, a white glowing spot was observed on the surface of the exposed sample. The presence of a glassy coating after laser irradiation is an indirect visual indicator for achieving the exposure required to melt the sample surface.

Powder X-ray diffraction (PXRD) patterns of the samples obtained were recorded on a D8 Advance powder diffractometer (Bruker AXS, Karlsruhe, Germany) with BraggBrentano geometry using $\mathrm{Cu}-\mathrm{K} \alpha$ radiation. PXRD patterns were collected in the interval $10^{\circ}<2 \Theta<90^{\circ}$ with a step size of $\Delta 2 \Theta=0.0195^{\circ}$ and a counting time of 53 s per step. Heating chamber HTK $1200 \mathrm{~N}$ with a volume of $1 \mathrm{~L}$ was used for high-temperature in situ diffraction measurements. The heating rate of the sample was $3^{\circ} \mathrm{C} / \mathrm{min}$. The unsintered sample was heated to a temperature of $1100^{\circ} \mathrm{C}$ in air; then, helium flow was supplied at a rate of $70 \mathrm{~mL} / \mathrm{min}$. Gaseous helium with a volume fraction of at least $99.995 \%$ was used. The volume fraction of water vapor was no more than $0.0005 \%$.

X-ray phase analysis of the samples was carried out using a PDF-4 database (ICDD, Release 2011). The unit cell parameters and crystallite size were refined by the Rietveld method using Topas 4.2 software (Bruker AXS, Karlsruhe, Germany).

Simultaneous thermal analysis was carried out using a Netzsch STA 449 F1 Jupiter device (NETZSCH, Selb, Germany) equipped with a QMS 403 C Aeolos mass-spectrometer (NETZSCH, Selb, Germany). The measurements were performed in a $\mathrm{Pt}-10 \mathrm{wt} \% \mathrm{Rh}$ covered crucible under an argon-oxygen mixture (80:20) at a heating rate of $10{ }^{\circ} \mathrm{C} / \mathrm{min}$. The mass of the analyzed sample was $30 \mathrm{mg}$.

Fourier transform infrared (FTIR) spectra were recorded on an Infralum-801 spectrometer (Simex, Novosibirsk, Russia) using the KBr pellet method.

The morphology of the ceramic surface was analyzed using a TM1000 scanning electron microscope (Hitachi, Tokyo, Japan).

The relative density of HA was evaluated from volumetric mass density of pellets, taking the theoretical density of hydroxyapatite as $3.156 \mathrm{~g} / \mathrm{cm}^{3}$. The volumetric mass density of pellets was estimated by the gravimetric method. The pycnometric density of pellets was measured by a helium picnometer Ultrapyc 1200e (Quantachrome Instruments, Boynton Beach, FL, USA) at $20.2^{\circ} \mathrm{C}$. Gaseous helium with a volume fraction of at least $99.99 \%$ was used. 


\section{Results and Discussion}

\subsection{Effect of the Ca/P Ratio on the Thermal Stability of HA}

Thermal stability of HA depends on the $\mathrm{Ca} / \mathrm{P}$ ratio. Almost all conventional synthesis methods of HA, with the exception of those using high-temperature processing, give a fine HA powder with defective nanosized particles. According to phase analysis, it is a single-phase apatite. Deviations in the $\mathrm{Ca} / \mathrm{P}$ ratio from the stochiometric value (1.667) upward or downward will not affect the analysis result due to the high defectiveness of the particles [31]. High-temperature treatment of this powder leads to annealing of the defects and an increase in the crystallite size with the formation of stoichiometric HA crystallites. With a lack of calcium or phosphate ions $(\mathrm{Ca} / \mathrm{P} \neq 1.667)$, both stoichiometric HA and impurity phases are formed.

As an example, Figure 1a shows the diffraction patterns of the HA samples prepared at different $\mathrm{Ca} / \mathrm{P}$ ratios by reactions (4)-(6). As seen, at $\mathrm{Ca} / \mathrm{P}$ ratios of 1.6, 1.667, and 1.7 , the diffraction patterns look identical, and all reflections belong to the HA phase. However, after sintering of non-stoichiometric samples $(\mathrm{Ca} / \mathrm{P}=1.6$ and 1.7), reflections of the impurity phases appear in the XRD patterns (Figure $1 \mathrm{~b}$ ). In the case of calcium-deficient $\mathrm{HA}(\mathrm{Ca} / \mathrm{P}=1.6)$, the $\beta-\mathrm{Ca}_{3}\left(\mathrm{PO}_{4}\right)_{2}$ phase is formed with a $\mathrm{Ca} / \mathrm{P}$ ratio of 1.5 , which is less than that of HA. With excess calcium cation $(\mathrm{Ca} / \mathrm{P}=1.7)$, the $\mathrm{CaO}$ reflection is observed in the XRD pattern. Prior to sintering, these impurity phases are not detected, because at a Ca/P ratio of 1.6, the calcium-deficient form of $\mathrm{HA} \mathrm{Ca}_{10-\mathrm{x}}\left(\mathrm{HPO}_{4}\right)_{\mathrm{x}}\left(\mathrm{PO}_{4}\right)_{6-\mathrm{x}}(\mathrm{OH})_{2-\mathrm{x}}$ is produced (Equation (4)), in which the calcium cation vacancies are occupied by protons of the $\mathrm{HPO}_{4}{ }^{2-}$ group [11]. With an excess of calcium cations $(\mathrm{Ca} / \mathrm{P}=1.7)$, the lack of the phosphate groups is compensated by the carbonate anions, resulting in the formation of carbonated hydroxyapatite $\mathrm{Ca}_{10-x}\left(\mathrm{PO}_{4}\right)_{6-x}\left(\mathrm{CO}_{3}\right)_{x}(\mathrm{OH})_{2-x}$ [32]. In this case, the yield of the resultant product increases slightly (Equation (6)). Both of these non-stoichiometric apatites are unstable at high temperatures, and therefore, upon heating, their decomposition with the formation of stoichiometric HA and the corresponding impurity phases occurs (Table 2).

The presence of the new phases in the sample decreases the relative density of sintered material (Table 2).
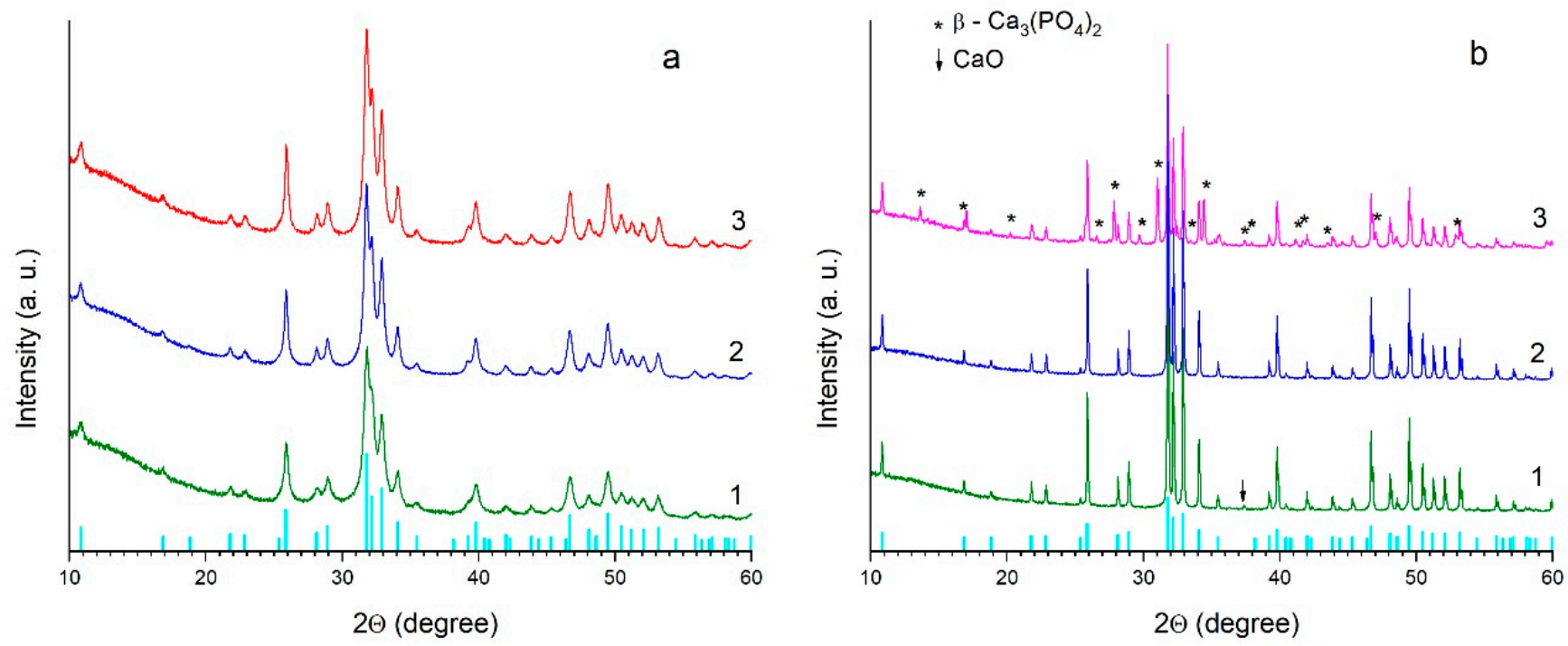

Figure 1. PXRD patterns of the as-synthesized HA powder (a) and samples obtained after $2 \mathrm{~h}$ of annealing at $1000{ }^{\circ} \mathrm{C}(\mathbf{b})$. $\mathrm{Ca} / \mathrm{P}$ ratios are 1.7 (1), 1.667 (2), and 1.6 (3). Vertical bars in the lower graphs correspond to the HA phase from the ICDD database (PDF No. 40-11-9308). 
Table 2. Phase composition, structural parameters of HA phase and relative density of the pellets with different Ca/P ratio before and after sintering in the high-temperature furnace.

\begin{tabular}{|c|c|c|c|c|c|c|c|}
\hline \multirow[b]{2}{*}{$\mathrm{Ca} / \mathrm{P}$ Ratio } & \multicolumn{3}{|c|}{ Content (wt $\%)$} & \multicolumn{3}{|c|}{ Structural Parameters of the HA Phase } & \multirow{2}{*}{$\begin{array}{l}\text { Relative Density } \\
(\%)\end{array}$} \\
\hline & HA & $\beta-\mathrm{Ca}_{3}\left(\mathrm{PO}_{4}\right)_{2}$ & $\mathrm{CaO}$ & $a(\AA)$ & $c(\AA)$ & $\begin{array}{c}\text { Crystallite Size } \\
(\mathrm{nm})\end{array}$ & \\
\hline \multicolumn{8}{|c|}{ Before sintering } \\
\hline 1.6 & 100 & - & - & $9.4394(10)$ & $6.8867(7)$ & $25.1(2)$ & 63.9 \\
\hline 1.667 & 100 & - & - & $9.4336(12)$ & $6.8932(9)$ & $29.0(4)$ & 64.9 \\
\hline 1.7 & 100 & - & - & $9.4374(16)$ & $6.8929(10)$ & $20.0(2)$ & 63.9 \\
\hline \multicolumn{8}{|c|}{ After sintering at $1000{ }^{\circ} \mathrm{C}, 2 \mathrm{~h}$} \\
\hline 1.6 & 72 & 28 & - & $9.4249(6)$ & $6.8813(5)$ & $99(2)$ & 77.1 \\
\hline 1.667 & 100 & - & - & $9.4240(2)$ & $6.8817(1)$ & $243(5)$ & 85.6 \\
\hline 1.7 & 99 & - & 1 & $9.4230(2)$ & $6.8814(2)$ & $209(4)$ & 76.9 \\
\hline
\end{tabular}

\subsection{Thermal Analysis of $H A$}

The results of thermal analysis of the stoichiometric HA powder are shown in Figure 2. According to Reaction (5), the mechanochemical synthesis of stoichiometric HA is accompanied by the release of two water molecules, which are adsorbed by HA particles. As seen from Figure 2, upon heating of the HA sample, adsorbed water and lattice water are released in a temperature range of $30-570{ }^{\circ} \mathrm{C}$. According to the data reported by Tõnsuaadu et al. [18], the dehydroxylation of HA with the removal of water molecules by Reaction (1) in air atmosphere starts at $900{ }^{\circ} \mathrm{C}$. In our case, this process probably starts at a lower temperature of $600{ }^{\circ} \mathrm{C}$ and proceeds up to temperatures above $1300{ }^{\circ} \mathrm{C}$ (Figure 2). The amount of released water increases as the temperature increases up to $1200^{\circ} \mathrm{C}$, and it almost does not change at high temperatures. Therefore, the reaction rate does not increase despite the increase in temperature. The kinetics of the reaction can be determined by the diffusion of water molecules inside the HA particles. During the reaction, the diffusion path increases, and the reaction is inhibited. Our estimations based on the data reported by Dorozhkin [33] suggest that the time required for water molecules to diffuse from a nanocrystal of $200 \mathrm{~nm}$ in size is about $20 \mathrm{~s}$. When carrying out differential thermal analysis, the heating rate was $10^{\circ} \mathrm{C} / \mathrm{min}$; therefore, it took $30 \mathrm{~min}$ to reach a temperature of $300{ }^{\circ} \mathrm{C}$, which is much longer than the calculated diffusion time for a water molecule. It can be assumed that the kinetics of the reaction is determined by the diffusion of water molecules through the channels between particles in the sample. Probably, significant shrinkage of the sample, which is due to the densification caused by the elimination of pores contained in the initial powder compact, makes the process of HA dehydroxylation difficult. At a temperature of $1200{ }^{\circ} \mathrm{C}$, the shrinkage is $20 \%$ of the initial volume [34]. In addition, the water molecule released during dehydroxylation is formed from a hydroxyl group and a proton from the adjacent hydroxyl group. Obviously, the probability of combining a proton and a hydroxyl group decreases as the number of hydroxyl groups in the channel decreases. All these factors should inhibit the process of HA dehydroxylation.

\subsection{Sintering of HA in a High-Temperature Furnace}

Stoichiometric HA samples, both as a powder and a compacted pellet, were heated in a high-temperature furnace. The results of the quantitative phase analysis of the samples and their lattice parameters after heating are shown in Table 3. As seen, the sample remains single phase up to a temperature of $1300^{\circ} \mathrm{C}$. According to the data presented in study [23], it can be assumed that the decomposition of HA with the formation of $\alpha$-tricalcium and tetracalcium phosphates at a water vapor pressure of $7 \mathrm{~mm} \mathrm{Hg}\left(25 \%\right.$ humidity at $\left.28{ }^{\circ} \mathrm{C}\right)$ should occur at temperatures above $1350{ }^{\circ} \mathrm{C}$. Indeed, a small content of the $\alpha-\mathrm{Ca}_{3}\left(\mathrm{PO}_{4}\right)_{2}$ phase is observed at $1400{ }^{\circ} \mathrm{C}$ in our case. At a temperature of $1500{ }^{\circ} \mathrm{C}$, the $\mathrm{Ca}_{4} \mathrm{O}\left(\mathrm{PO}_{4}\right)_{2}$ phase is also detected. Concentration of the decomposition products increases as the time 
of treatment increases, and it is accompanied by a decrease in the pycnometric density (Table 3). The pycnometric densities of the sintered pellets reach their maximum values at $1300{ }^{\circ} \mathrm{C}$.

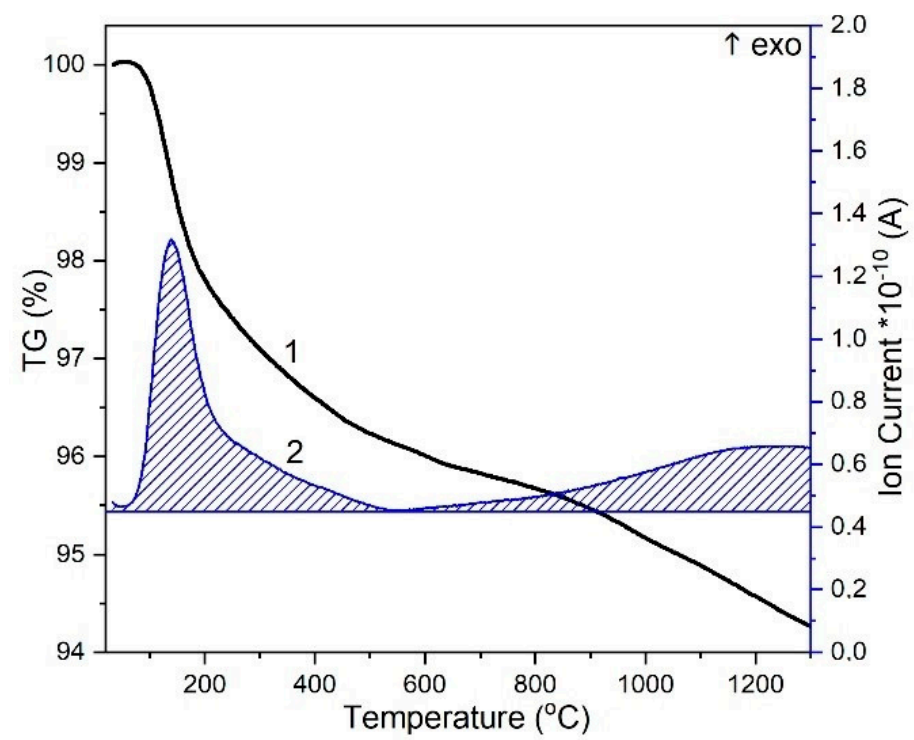

Figure 2. Simultaneous thermal analysis of the HA powder: 1 -weight loss; 2 - evolved water.

Table 3. Phase composition and structural parameters of the stoichiometric HA sample after sintering in the hightemperature furnace at different temperatures and at a heating rate of $5^{\circ} / \mathrm{min}$.

\begin{tabular}{|c|c|c|c|c|c|c|c|c|c|}
\hline \multirow{2}{*}{$\begin{array}{c}\text { Temperature } \\
\left({ }^{\circ} \mathrm{C}\right)\end{array}$} & \multicolumn{4}{|c|}{ Content (wt\%) } & \multicolumn{3}{|c|}{$\begin{array}{l}\text { Structural Parameters of the } \\
\text { HA Phase }\end{array}$} & \multirow[b]{2}{*}{ Strain } & \multirow{2}{*}{$\begin{array}{c}\text { Pycnometric } \\
\text { Density } \\
\text { (g/cc) }\end{array}$} \\
\hline & $\alpha-\mathrm{Ca}_{3}\left(\mathrm{PO}_{4}\right)_{2}$ & $\mathrm{Ca}_{4} \mathrm{O}\left(\mathrm{PO}_{4}\right)_{2}$ & $\mathrm{CaO}$ & HA & $a(\AA)$ & $c(\AA)$ & $\begin{array}{l}\text { Crystallite } \\
\text { Size (nm) }\end{array}$ & & \\
\hline \multicolumn{10}{|c|}{ HA powder, duration of sintering $10 \mathrm{~min}$} \\
\hline 1100 & - & - & - & 100 & $9.4250(1)$ & $6.8821(1)$ & $317(8)$ & - & - \\
\hline 1200 & - & - & - & 100 & $9.4233(2)$ & 6.8831(1) & $551(20)$ & - & - \\
\hline 1300 & - & - & - & 100 & 9.4196(1) & 6.8869(1) & $768(66)$ & $0.048(4)$ & - \\
\hline 1400 & 3 & - & - & 97 & $9.4179(2)$ & $6.8867(2)$ & 252(12) & $0.057(7)$ & - \\
\hline 1500 & 26 & 14 & - & 60 & $9.4172(6)$ & $6.8861(6)$ & $139(8)$ & $0.19(1)$ & - \\
\hline \multicolumn{10}{|c|}{ HA powder, duration of sintering $2 \mathrm{~h}$} \\
\hline 1000 & - & - & - & 100 & $9.4232(2)$ & $6.8822(2)$ & 183(6) & - & - \\
\hline 1100 & - & - & - & 100 & $9.4227(3)$ & 6.8845(1) & $405(20)$ & - & - \\
\hline 1200 & - & - & - & 100 & $9.4215(1)$ & 6.8862(1) & $762(50)$ & $0.024(4)$ & - \\
\hline 1300 & - & - & - & 100 & 9.4180(1) & 6.8885(1) & $425(26)$ & $0.053(5)$ & - \\
\hline 1400 & 8 & - & - & 92 & 9.4182(1) & $6.8878(2)$ & $372(20)$ & $0.081(4)$ & - \\
\hline 1500 & 43 & 22 & - & 35 & $9.4181(1)$ & $6.8878(1)$ & $111(9)$ & $0.22(1)$ & - \\
\hline \multicolumn{10}{|c|}{ HA pellet, duration of sintering $10 \mathrm{~min}$} \\
\hline 1100 & - & - & - & 100 & $9.4237(1)$ & $6.8820(1)$ & $391(20)$ & - & $3.068(7)$ \\
\hline 1200 & - & - & - & 100 & $9.4224(3)$ & $6.8828(2)$ & $349(24)$ & $0.122(6)$ & $3.126(19)$ \\
\hline 1300 & - & - & - & 100 & $9.4181(2)$ & $6.8877(2)$ & $495(36)$ & $0.118(4)$ & $3.169(6)$ \\
\hline 1400 & 2 & - & - & 98 & $9.4118(6)$ & 6.8903(4) & 441(58) & $0.330(9)$ & 3.117(19) \\
\hline 1500 & 19 & - & - & 81 & $9.4170(8)$ & $6.8877(5)$ & $225(23)$ & $0.33(1)$ & $2.905(6)$ \\
\hline \multicolumn{10}{|c|}{ HA pellet, duration of sintering $2 \mathrm{~h}$} \\
\hline 1500 & 50 & 14 & 1 & 35 & $9.4094(12)$ & $6.8811(14)$ & $304(70)$ & $0.34(4)$ & $2.909(6)$ \\
\hline
\end{tabular}

With regard to the structural parameters of the HA phase, it can be noted that when increasing the sintering temperature, a decrease in the lattice parameter $a$ of the cooled sample occurs (Table 3). The lattice parameter $c$ shows a very small increase with small fluctuations at decomposition temperatures of $\mathrm{HA}\left(1400,1500{ }^{\circ} \mathrm{C}\right)$. A decrease in the $a$ value is obviously related to a decrease in the diameter of the hydroxyl channel caused 
by a gradual increase in the $\mathrm{OH}$ vacancy concentration and the presence of the $\mathrm{O}^{2-}$ ions (Equation (1)). A minimum value of the parameter $a$ was achieved for a pellet treated at $1500{ }^{\circ} \mathrm{C}$ for $2 \mathrm{~h}$. It may be assumed that this sample contains a minimum concentration of the $\mathrm{OH}^{-}$groups, and the FTIR spectra support this (Figure 3). As seen from the spectrum, the intensity of the libration $\left(632 \mathrm{~cm}^{-1}\right)$ and stretching $\left(3570 \mathrm{~cm}^{-1}\right)$ vibrations of the $\mathrm{OH}$ group for this sample is close to zero. Therefore, it can be concluded that the pellet sintered at $1500^{\circ} \mathrm{C}$ for $2 \mathrm{~h}$ contains both the decomposition products and an almost completely dehydroxylated OA phase. Accordingly, the lattice parameters $a=9.4094$ (12) $\AA$ and $c=6.8811$ (14) $\AA$ can be considered close to the values of stoichiometric OA. Atomic parameters of the OA phase cannot be refined by the Rietveld method due to its low content in the sample (only $35 \mathrm{wt} \%$ ) and the overlapping of its reflections with those of the new phases. It can be assumed that when sintering HA in the pellet form, rehydroxylation upon cooling is difficult due to there being much less interpore space in the pellet as compared to that of the powder.

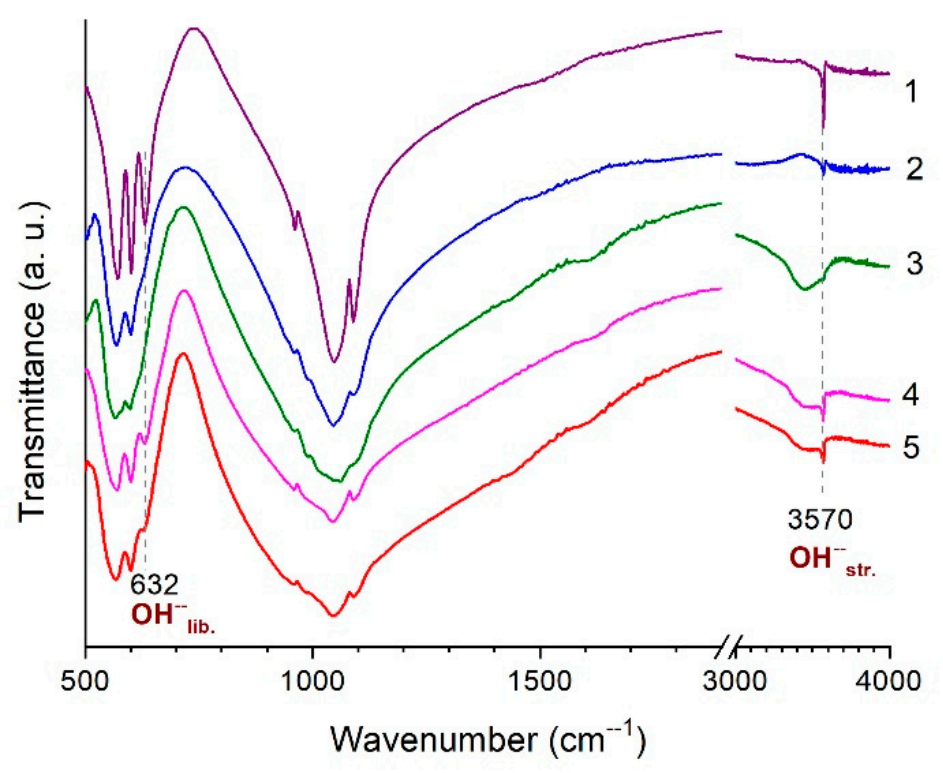

Figure 3. FTIR spectra of HA samples after sintering in a high-temperature furnace: (1) powder after $1000{ }^{\circ} \mathrm{C}$ during $2 \mathrm{~h}$; (2) pellet after $1500{ }^{\circ} \mathrm{C}$ during $10 \mathrm{~min}$; (3) pellet after $1500{ }^{\circ} \mathrm{C}$ during $2 \mathrm{~h}$; (4) powder after $1500{ }^{\circ} \mathrm{C}$ during $10 \mathrm{~min}$; (5) powder after $1500^{\circ} \mathrm{C}$ during $2 \mathrm{~h}$.

It should also be noted that the crystallite size increases when the sintering temperature increases to $1300{ }^{\circ} \mathrm{C}$ (Table 3). At higher temperatures, the crystallite size starts to decrease, while the concentration of decomposition products increases. Consequently, the HA decomposition takes place in the surface layer of the OHA particles.

Table 3 shows the strain effects observed at high temperatures both in the pellets and in the sintered powders. As seen, it starts from 1200 or $1300{ }^{\circ} \mathrm{C}$ and increases with increasing the temperature, making the structure more stressed. The strain value depends on the duration of the temperature treatment (the longer the treatment, the higher the strain) and on the sample density (the pellet has a higher strain rate).

The long treatment of the $\mathrm{HA}$ pellet during $10 \mathrm{~h}$ at a temperature of $1500{ }^{\circ} \mathrm{C}$ results in the formation of a large number of crystals on the surface of HA pellet (Figure 4a). As seen at higher magnification, they are monocrystalline with different crystal facets (Figure $4 \mathrm{~b}$ ). Apparently, these single crystals are the decomposition products, such as $\alpha-\mathrm{Ca}_{3}\left(\mathrm{PO}_{4}\right)_{2}$, $\mathrm{Ca}_{4} \mathrm{O}\left(\mathrm{PO}_{4}\right)_{2}$, and $\mathrm{CaO}$.

The formation of the partial decomposition products of apatite at high temperatures indicates that the congruent melting of stoichiometric HA cannot be achieved by heating in an oven. 


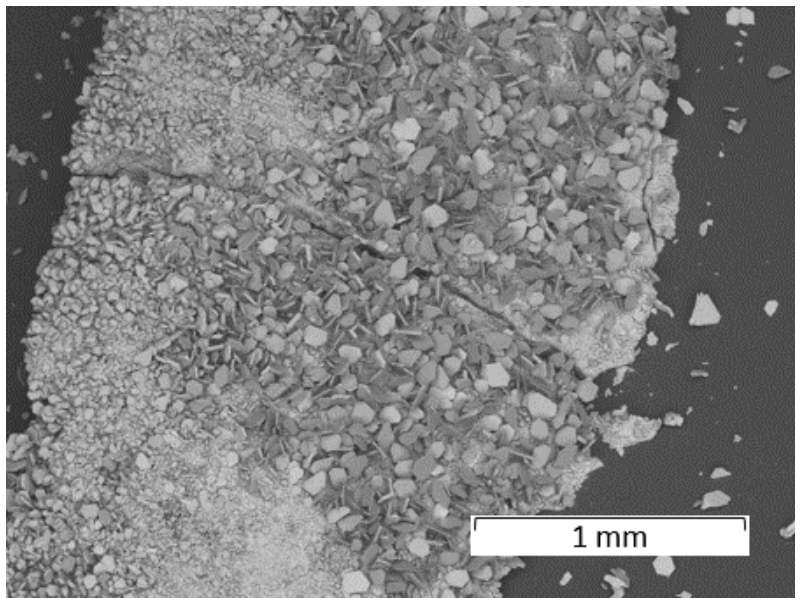

(a)

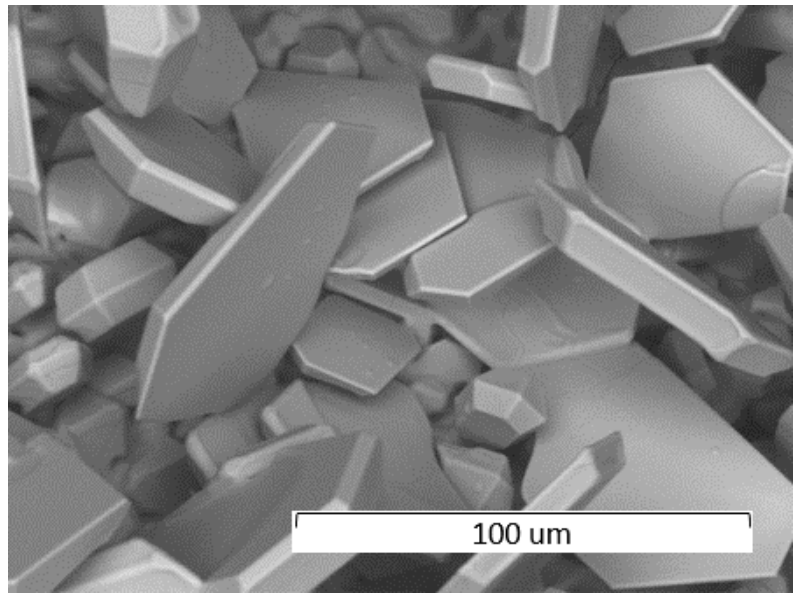

(b)

Figure 4. SEM images of the crystals obtained on the surface of HA pellet after treatment at $1500{ }^{\circ} \mathrm{C}$ during $10 \mathrm{~h}$ : (a) general view; (b) enlarged view.

\subsection{High-Temperature In Situ Diffraction}

Figure 5a shows in situ diffraction patterns of the sample during the heating of unsintered stoichiometric HA pellet in air. As seen, the sample remains single phase in the temperature range $25-1100^{\circ} \mathrm{C}$. Reflections presented in the PXRD pattern indicated that the HA had a hexagonal structure with the space group $P 6_{3} / m$ (ICDD, PDF 40-11-9308). When changing the air medium to helium flow at $1100^{\circ} \mathrm{C}$, the phase composition does not change either; however, there is quite a noticeable shift in the positions of some reflections (Figure 5b).
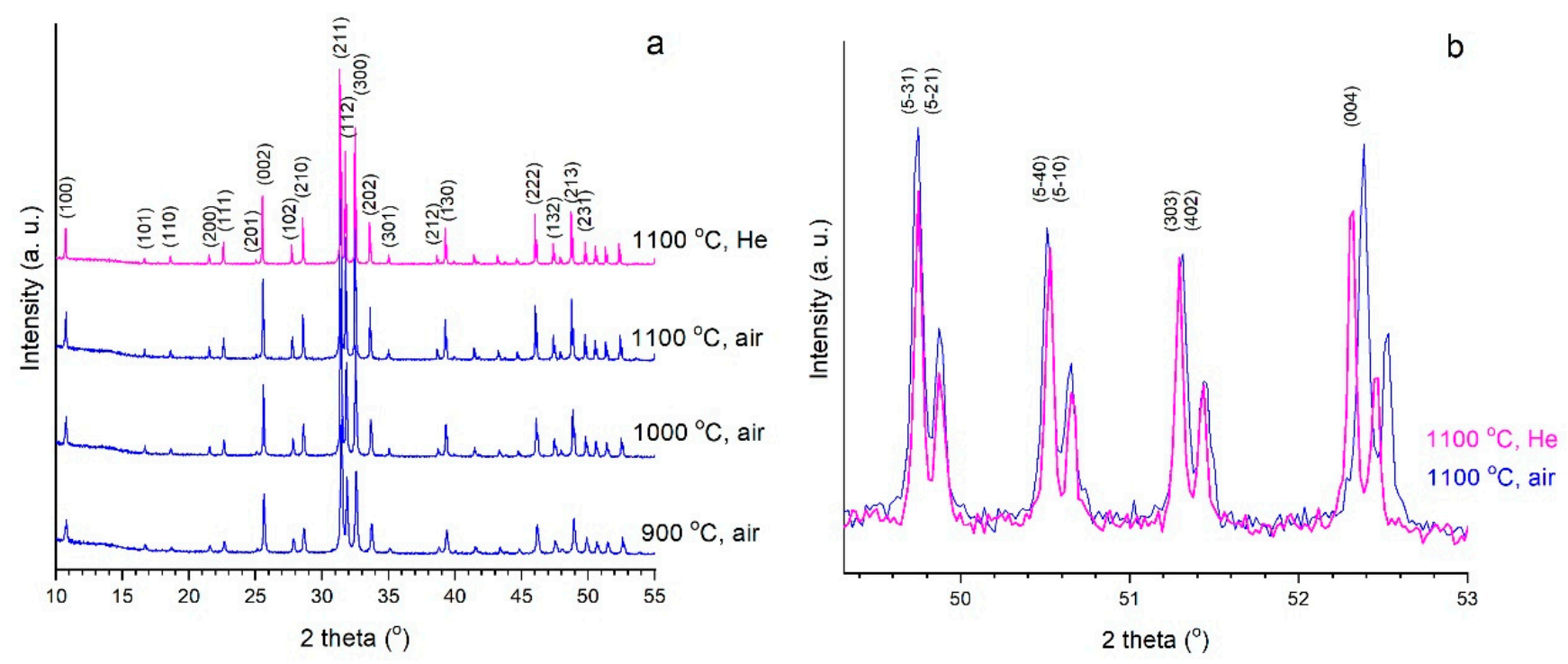

Figure 5. In situ PXRD patterns of the HA pellets heated at different temperatures in air and in helium flow; (a) - general view, (b) - enlarged view of the $49.4-53^{\circ} 2 \theta$ region.

The unit cell parameters and its volume increase linearly as the temperature increases (Figure 6). When changing the air medium to a helium flow, a decrease in the parameter $a$ and an increase in the parameter $c$ are observed, whereas the volume of the HA unit cell does not change significantly. The use of helium flow instead of the air medium accelerates the dehydroxylation process of HA. The pellets cooled in air and in helium media have comparable values of the lattice parameters (Table 4), while the $a$ values are significantly different from those given in Table 3 for the samples heated in a high-temperature furnace to 
the same temperature in air. This can be explained by the different volumes and the design features of the high-temperature chambers, leading to different convection conditions inside the chambers and different water partial pressure. The volume of the chamber used for in situ experiments was five times smaller, and, consequently, the amount of water vapor therein was not enough for the rehydroxylation of OHA. Therefore, the $a$ parameter of the pellet cooled in the in situ chamber is smaller. The FTIR spectroscopy data support this (Figure 7). As seen from the absorption spectra of the samples, after in situ heat treatment, the intensity of the stretching and libration vibrations of the $\mathrm{OH}$ group is much less than that after heating in the furnace.

It should also be noted that in the PXRD patterns of both the heated and cooled samples, there are no reflections indicating the change of the hexagonal space group to the monoclinic $P 2_{1} / b$ as was observed by other authors [9]. A splitting of reflections, which was reported by Alberius et al. and Gross et al. [35,36], was not observed, either.

\subsection{Extremal Heating Conditions}

As shown above, the congruent melting of HA by heating in a furnace at rates no more than $5{ }^{\circ} \mathrm{C} / \mathrm{min}$ cannot be achieved. Given the fact that the process of dehydroxylation of $\mathrm{HA}$, which eventually leads to its decomposition, proceeds rather slowly, it can be assumed that the stage of HA decomposition can be avoided by rapid heating. Therefore, it was of interest to find out whether the melting of $\mathrm{HA}$ at high heating rates would be congruent.

Ultrafast heating of HA can be achieved using plasma and detonation spraying or laser treatment [37]. In this case, heating to the melting point occurs in a fraction of a second. Under these treatment conditions, the possibility of overheating of HA due to very high processing temperatures is very high; therefore, incongruent melting of HA coupled with the partial dehydroxylation and partial decomposition of HA takes place.

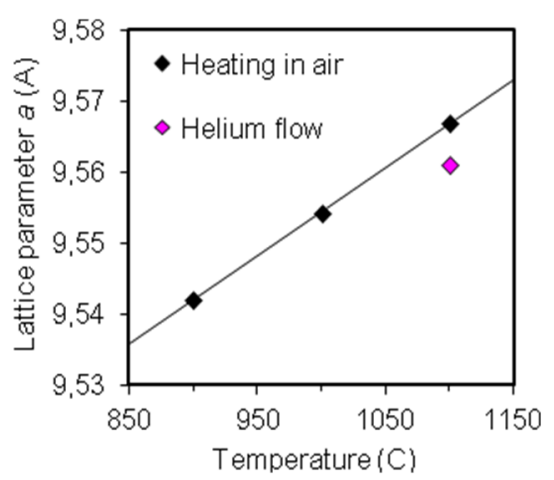

(a)

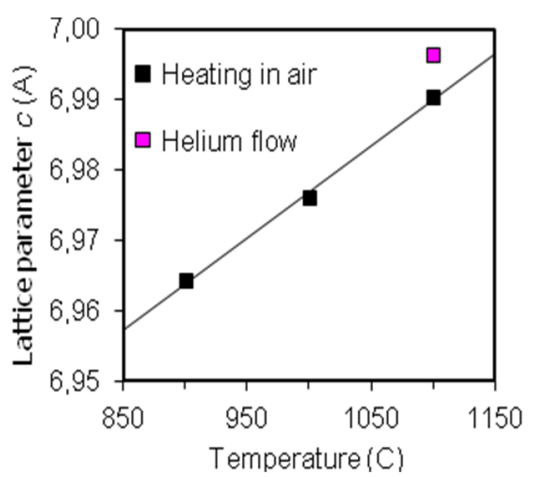

(b)

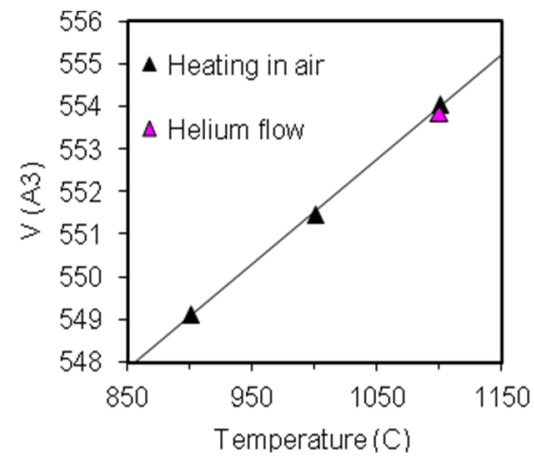

(c)

Figure 6. Variation of the lattice parameters $(\mathbf{a}, \mathbf{b})$ and volume $(\mathbf{c})$ as a function of temperature for the HA pellet at in situ experiment.

Table 4. Structural parameters for the HA phase treated under various conditions in in situ experiments. The data are given for the sample cooled at room temperature.

\begin{tabular}{|c|c|c|c|c|c|c|}
\hline Heat Conditions & Sample State & $a(\AA)$ & $c(\AA)$ & $V\left(\AA^{3}\right)$ & Crystallite Size (nm) & Strain \\
\hline $\begin{array}{l}\text { Heating up to } 1100{ }^{\circ} \mathrm{C} \text { in } \\
\text { air, cooling in air }\end{array}$ & Pellet & $9.41663(3)$ & $6.88542(3)$ & $528.752(4)$ & $542(10)$ & $0.025(1)$ \\
\hline $\begin{array}{l}\text { Heating up to } 1100^{\circ} \mathrm{C} \text { in } \\
\text { air, cooling in } \mathrm{He} \text { flow }\end{array}$ & Pellet & $9.41497(6)$ & $6.88443(5)$ & $528.490(8)$ & $321(5)$ & $0.101(1)$ \\
\hline Selective laser melting & Pellet & $9.4139(8)$ & $6.8902(6)$ & $528.82(9)$ & 197(18) & $0.35(2)$ \\
\hline
\end{tabular}




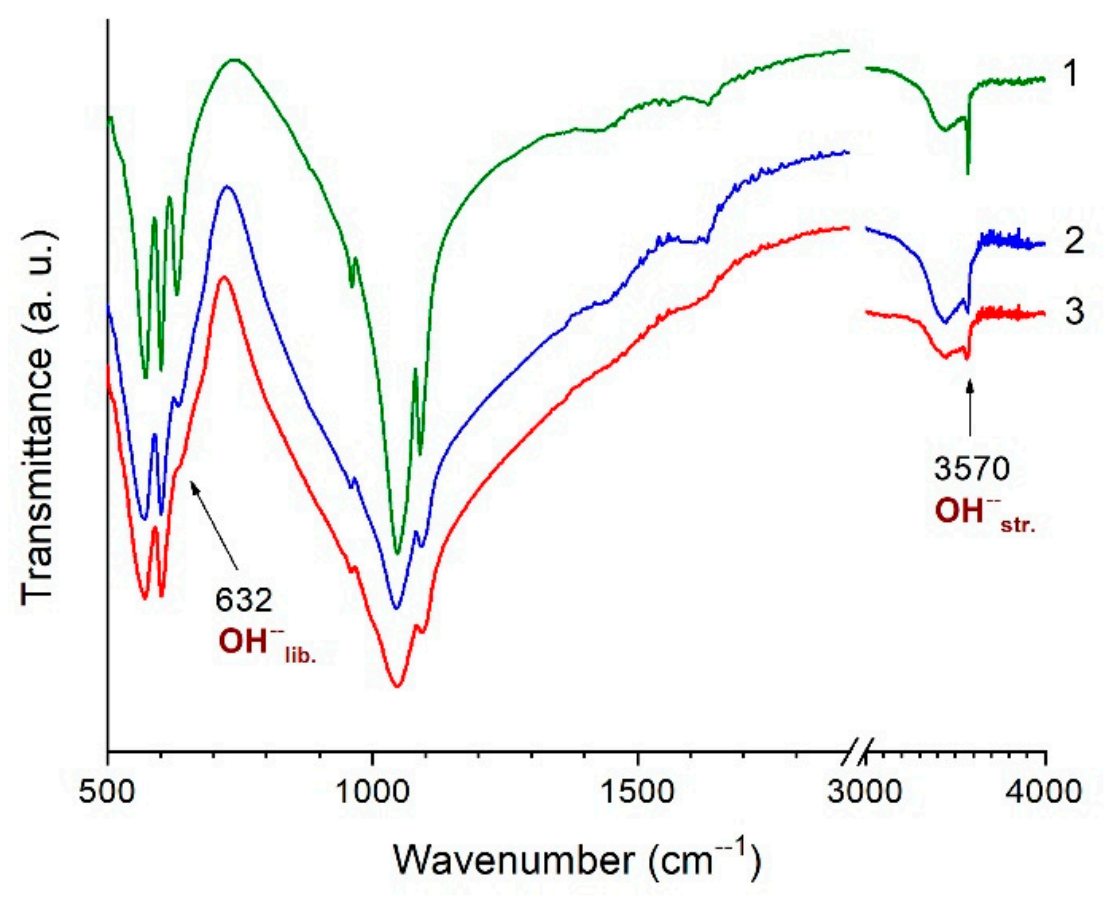

Figure 7. IR spectra of HA samples after heating under different conditions: (1) pellet, heating in a PVK-1.6 furnace to $1100{ }^{\circ} \mathrm{C}$, cooling in air; (2) pellet, heating in an in situ chamber HTK $1200 \mathrm{~N}$, cooling in air; (3) pellet, heating in an in situ chamber HTK $1200 \mathrm{~N}$, cooling in a flow of helium.

However, under certain experimental conditions, using selective laser melting technology, HA can be melted without decomposition. For instance, under the $\mathrm{CO}_{2}$ laser treatment of the stoichiometric HA pellet surface at a spot size of $0.2 \mathrm{~mm}$, at a power of $4 \mathrm{~W}$, and at a scanning speed of $500 \mathrm{~mm} / \mathrm{s}$, a dense layer of recrystallized OHA is obtained (Figure $8 \mathrm{a}, \mathrm{c}$ ). In this case, melting occurs for $10^{-4} \mathrm{~s}$. In such a short time, the melt does not lose a large number of $\mathrm{OH}$ groups, so the decomposition of $\mathrm{HA}$ is not observed. Obviously, the melt crystallization starts from the lower layer, and the unmelted particles of HA are the nuclei for crystallization. As a result of the competitive growth of crystallites with different orientations, the most rapidly growing crystallites have an advantage. Thus, a directed growth of the predominantly oriented crystallites is observed. As seen in the PXRD patterns of the recrystallized sample, the crystallites are predominantly oriented in the [002] direction (Figure 9a). The lattice parameters of this recrystallized layer correspond to the OHA crystalline phase (Table 4). Unfortunately, precisely measuring the melting point of the material under these conditions is difficult, since the area of the localized heat exposure is $0.2 \mathrm{~mm}$, while the duration of the exposure is $10^{-4} \mathrm{~s}$.

A decrease in the speed of the laser spot moving over the surface of the HA pellet to $200 \mathrm{~mm} / \mathrm{s}$ leads to the formation of a thicker recrystallized layer (Figure 8b,d) with a more predominant orientation in the [002] direction (Figure 9b). However, in this case, the most intense reflection of the decomposition product $\alpha-\mathrm{Ca}_{3}\left(\mathrm{PO}_{4}\right)_{2}$ appears in the PXRD pattern of the recrystallized layer (Figure $9 \mathrm{~b}$ ). In this treatment mode, the time of intensive heat exposure is $10^{-3} \mathrm{~s}$, which is still insufficient for significant water removal. However, a slower surface treatment leads to an increase in exposure and therefore to an increase in the transmitted energy, i.e., it leads to an increase in temperature, resulting in the partial decomposition of the material. 


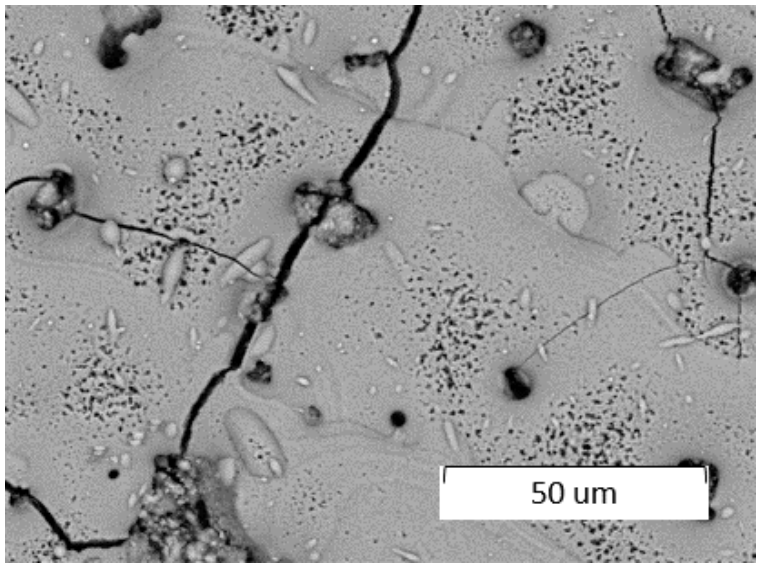

(a)

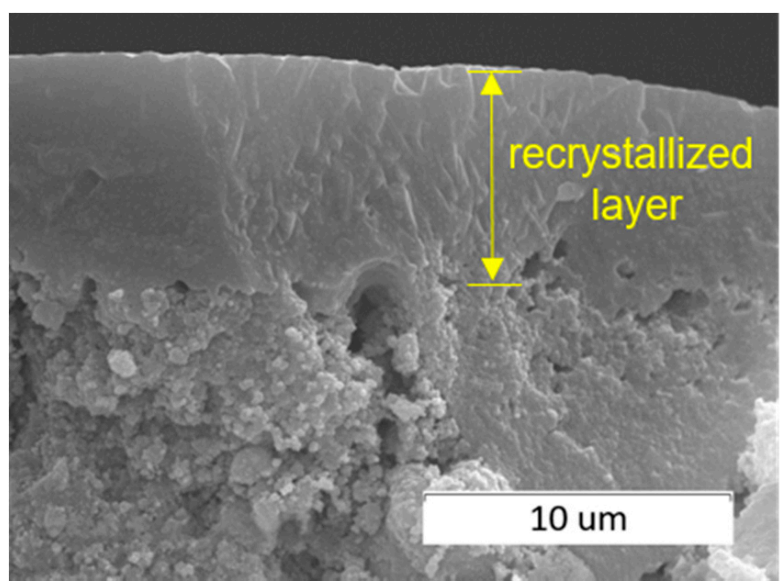

(c)

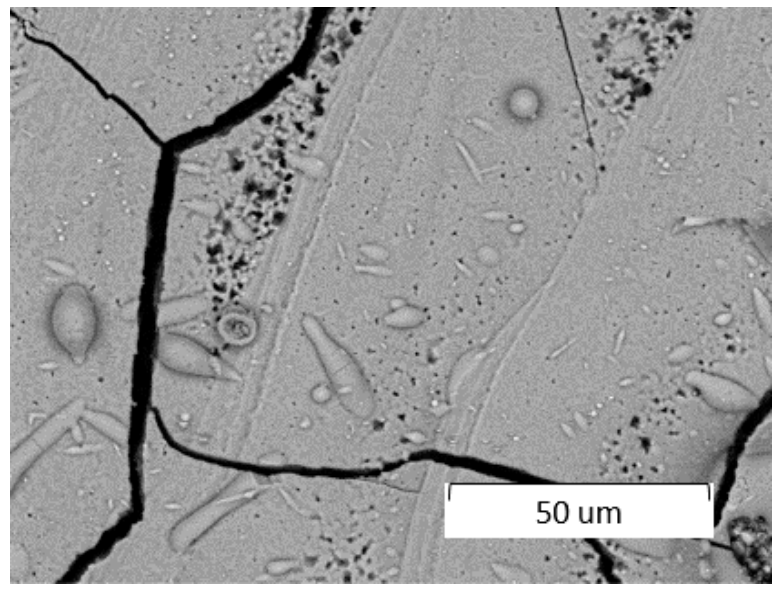

(b)

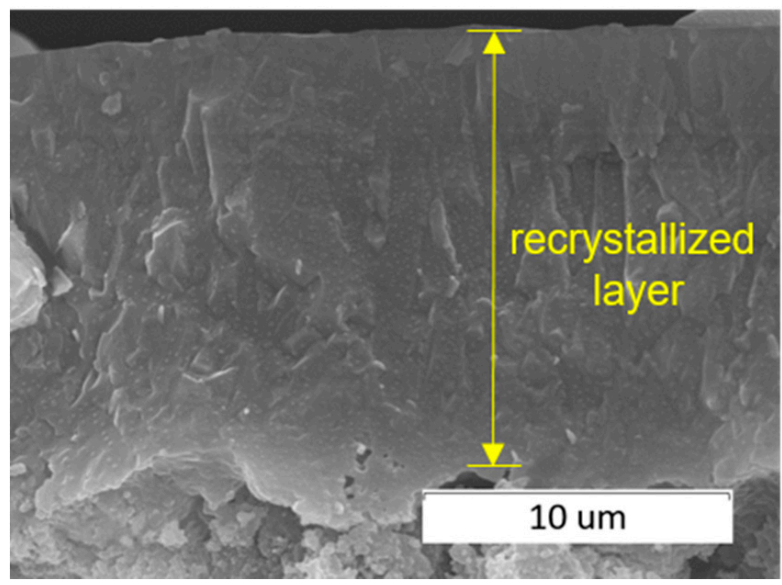

(d)

Figure 8. SEM images of surface $(\mathbf{a}, \mathbf{b})$ and cross-section $(\mathbf{c}, \mathbf{d})$ of the pellets treated by a $0.2 \mathrm{~mm}$ laser spot at $4 \mathrm{~W}$ and at scanning speeds of $500 \mathrm{~mm} / \mathrm{s}(\mathbf{a}, \mathbf{c})$ and $200 \mathrm{~mm} / \mathrm{s}(\mathbf{b}, \mathbf{d})$.
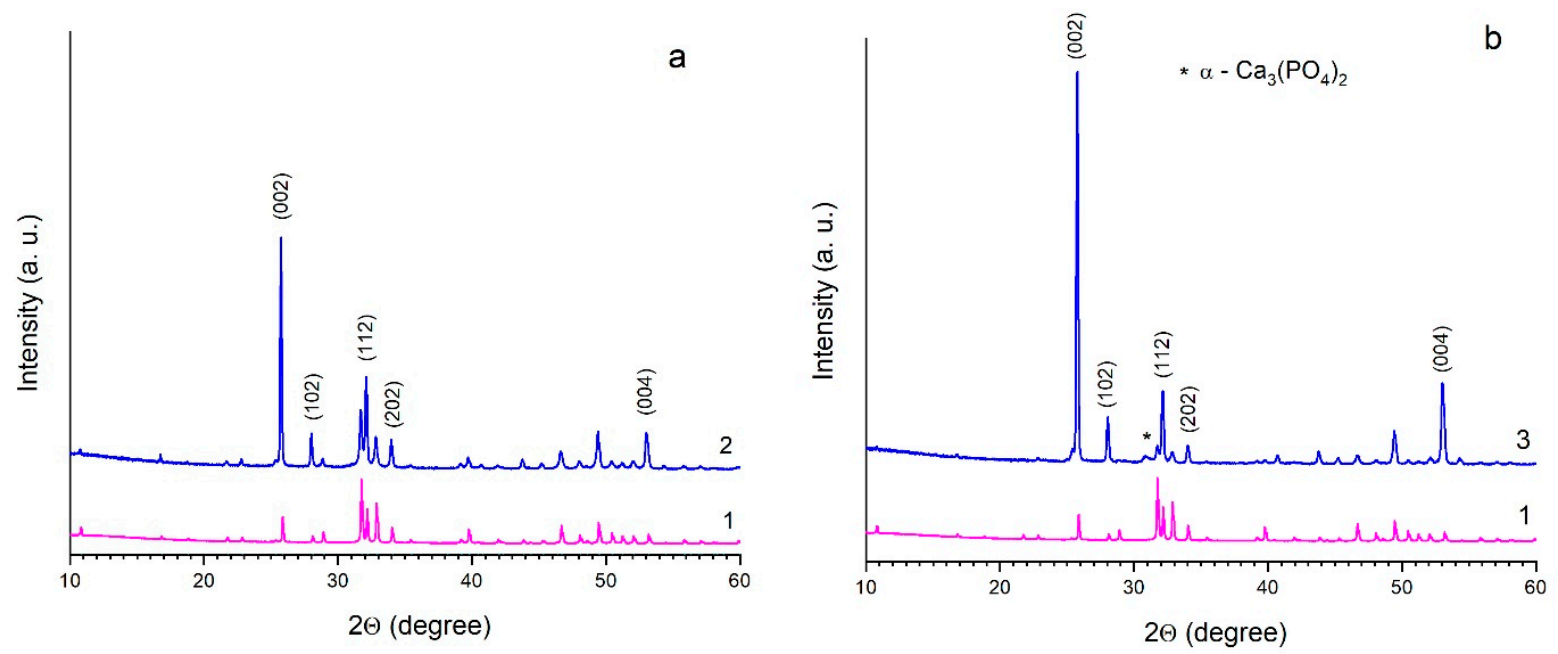

Figure 9. PXRD patterns of HA pellets after sintering at $1000^{\circ} \mathrm{C}$ in a high-temperature furnace (1) in comparison with PXRD patterns of HA pellets after treatment by a $0.2 \mathrm{~mm}$ laser spot at $4 \mathrm{~W}$ and different scanning speeds: (a) - $500 \mathrm{~mm} / \mathrm{s}$ (2); (b) $-200 \mathrm{~mm} / \mathrm{s}(3)$. 


\section{Conclusions}

The crystal structure of HA is conducive to different types of cationic and anionic substitutions, while in the case of incomplete substitution, the formation of solid solutions takes place. Some types of substitutions significantly reduce the HA thermal stability. This study shows that if the proper synthesis conditions are not maintained, the calcium-deficient or carbonated HA are formed. These types of apatite are less stable than stoichiometric HA at high temperatures. Upon high-temperature treatment $\left(\geq 900^{\circ} \mathrm{C}\right)$, they are decomposed into stoichiometric HA and corresponding impurities, which can affect negatively the strength characteristics of the produced ceramics.

The stoichiometric HA produced by the solid-state mechanochemical method was shown to have a hexagonal structure with the space group $P 6_{3} / \mathrm{m}$. The sample remains single-phase up to a temperature of $1300^{\circ} \mathrm{C}$ during sintering both as a powder and a pellet. At higher temperatures, the partial decomposition of HA occurs, which is preceded by the dehydroxylation of HA with the formation of OHA. Dehydroxylation does not lead to any phase transitions, but it is accompanied by changes in the size of the crystal lattice, such as a decrease in the $a$ parameter and an increase in the $c$ parameter. At temperatures above $1200{ }^{\circ} \mathrm{C}$, microstrains appear in the structure. An increase in the density of the sample under sintering results in an increase in the microstrains.

A sample containing an apatite phase with a negligible amount of the hydroxyl groups, which could approximately be attributed to $\mathrm{OA}$, was prepared. It may be assumed that $\mathrm{OA}$ is the end member in the $\mathrm{Ca}_{10}\left(\mathrm{PO}_{4}\right)_{6}(\mathrm{OH})_{2-2 \mathrm{x}} \mathrm{O}_{\mathrm{x}} \square_{\mathrm{x}}$ solid solution series with the space group $P 6_{3} / m$ and the lattice parameters $a=9.4094(12) \AA$ and $c=6.8811(14) \AA$.

At temperatures above $1300{ }^{\circ} \mathrm{C}$, the decomposition of OA occurs in the sample with the formation of more stable new phases of calcium phosphates and calcium oxide. The content of the decomposition products is affected by the duration of treatment of the sample and its density. The OA decomposition takes place in the upper layers of the particles due to which the size of the apatite crystallites decreases as the concentration of decomposition products increases. The decomposition products reduce the material density.

Thus, slow heating of stoichiometric $\mathrm{HA}$ in a high-temperature furnace ( $V_{\text {heating }} \leq 5{ }^{\circ} \mathrm{C} / \mathrm{min}$ ) to a temperature of $1500{ }^{\circ} \mathrm{C}$ in air results in the following transformations:

$\mathrm{HA} \rightarrow \mathrm{OHA} \rightarrow \mathrm{OHA}+\mathrm{OA} \rightarrow \mathrm{OHA}+\mathrm{OA}+\alpha-\mathrm{Ca}_{3}\left(\mathrm{PO}_{4}\right)_{2} \rightarrow \mathrm{OHA}+\mathrm{OA}+\alpha-\mathrm{Ca}_{3}\left(\mathrm{PO}_{4}\right)_{2}$ $+\mathrm{Ca}{ }_{4} \mathrm{O}\left(\mathrm{PO}_{4}\right)_{2} \rightarrow \mathrm{OA}+\alpha-\mathrm{Ca}_{3}\left(\mathrm{PO}_{4}\right)_{2}+\mathrm{Ca}{ }_{4} \mathrm{O}\left(\mathrm{PO}_{4}\right)_{2}+\mathrm{CaO}$.

Therefore, the congruent melting of stoichiometric HA upon heating in a hightemperature furnace does not occur.

On fast heating $\left(\mathrm{V}_{\text {heating }}>1000{ }^{\circ} \mathrm{C} / \mathrm{s}\right)$ of stoichiometric HA by laser irradiation, under certain conditions, the congruent melting of OHA can be achieved. The fast heating and cooling, in this case, reduce the number of hydroxyl groups, leaving the OHA structure and thus allowing it to melt without decomposition. The recrystallized layer has a dense structure predominantly oriented in the [002] direction. The process of congruent melting of HA can be used to produce bulk ceramic products by layer-by-layer melting of apatite powder (3D printing). In addition, it can be assumed that congruent HA melting can also be achieved when using other methods, providing similar heating rates.

This study shows that the process of thermal treatment of HA depends on its synthesis conditions, on its morphology and dispersibility, heat treatment conditions, and how far they are from thermodynamic equilibrium. Since HA heating is accompanied by the removal of $\mathrm{OH}$ groups with the formation of water molecules, both temperature and the water vapor pressure affect the thermal stability of HA. These factors should be taken into account when selecting sintering modes to produce ceramic products.

Author Contributions: Conceptualization, N.V.B.; methodology, N.V.B.; investigation, S.V.M., S.G.B. and K.B.G.; writing—original draft preparation, N.V.B.; writing—review and editing, A.A.M., K.B.G., O.A.L. and V.S.B.; funding acquisition, V.S.B. All authors have read and agreed to the published version of the manuscript. 
Funding: The study was supported by a grant Russian Science Foundation (RSF), No. 21-12-00251.

Data Availability Statement: The raw/processed data required to reproduce these results are included in the Materials and Methods section.

Conflicts of Interest: The authors declare no conflict of interest. The funders had no role in the design of the study; in the collection, analyses, or interpretation of data; in the writing of the manuscript; or in the decision to publish the results.

\section{References}

1. Elliott, J.C. Structure and Chemistry of the Apatites and Other Calcium Orthophosphates; Studies in Inorganic Chemistry; Elsevier: Amsterdam, The Netherlands, 1994; pp. 1-404.

2. Šupová, M. Substituted hydroxyapatites for biomedical applications: A review. Ceram. Int. 2015, 41, 9203-9231. [CrossRef]

3. White, T.J.; Zhili, D. Structural derivation and crystal chemistry of apatites. Acta Crystallogr. B 2003, 59, 1-16. [CrossRef] [PubMed]

4. Ratnayake, J.T.B.; Mucalo, M.; Dias, G.J. Substituted hydroxyapatites for bone regeneration: A review of current trends. J. Biomed. Mater. Res. B Appl. Biomater. 2017, 105, 1285-1299. [CrossRef] [PubMed]

5. Sadat-Shojai, M.; Khorasani, M.-T.; Dinpanah-Khoshdargi, E.; Jamshidi, A. Synthesis methods for nanosized hydroxyapatite with diverse structures. Acta Biomater. 2013, 9, 7591-7621. [CrossRef] [PubMed]

6. Lin, K.; Wu, C.; Chang, J. Advances in synthesis of calcium phosphate crystals with controlled size and shape. Acta Biomater. 2014, 10, 4071-4102. [CrossRef]

7. Chaikina, M.V.; Bulina, N.V.; Vinokurova, O.B.; Prosanov, I.Y.; Dudina, D.V. Interaction of calcium phosphates with calcium oxide or calcium hydroxide during the "soft" mechanochemical synthesis of hydroxyapatite. Ceram. Int. 2019, 45, 16927-16933. [CrossRef]

8. Ma, G.; Liu, X.Y. Hydroxyapatite: Hexagonal or monoclinic? Cryst. Growth Des. 2009, 9, 2991-2994. [CrossRef]

9. Pastero, L.; Bruno, M.; Aquilano, D. About the Genetic Mechanisms of Apatites: A Survey on the Methodological Approaches. Minerals 2017, 7, 139. [CrossRef]

10. Wilson, R.M.; Elliott, J.C.; Dowker, S.E.; Rodríguez-Lorenzo, L.M. Rietveld refinements and spectroscopic studies of the structure of Ca-deficient apatite. Biomaterials 2005, 26, 1317-1327. [CrossRef]

11. Dorozhkin, S.V. Calcium orthophosphates $\left(\mathrm{CaPO}_{4}\right)$ : Occurrence and properties. Prog. Biomater. 2016, 5, 9-70. [CrossRef]

12. Córdova-Udaeta, M.; Kim, Y.; Yasukawa, K.; Kato, Y.; Fujita, T.; Dodbiba, G. Study on the Synthesis of Hydroxyapatite under Highly Alkaline Conditions. Ind. Eng. Chem. Res. 2021, 60, 4385-4396. [CrossRef]

13. Mucalo, M. Hydroxyapatite (HAp) for Biomedical Applications; Woodhead Publishing Limited: Waltham, MA, USA, $2015 ;$ pp. 1-364.

14. Kenny, S.M.; Buggy, M. Bone cements and fillers: A review. J. Mater. Sci. Mater. Med. 2003, 14, 923-938. [CrossRef] [PubMed]

15. Gruselle, M. Apatites: A new family of catalysts in organic synthesis. J. Organomet. Chem. 2015, 793, 93-101. [CrossRef]

16. Dorozhkin, S.V. Current State of Bioceramics. J. Ceram. Sci. Technol. 2018, 9, 353-370. [CrossRef]

17. Dorozhkin, S. Calcium Orthophosphate $\left(\mathrm{CaPO}_{4}\right)$ Scaffolds for Bone Tissue Engineering Applications. J. Biotechnol. Biomed. Sci. 2018, 1, 25-93. [CrossRef]

18. Tõnsuaadu, K.; Gross, K.A.; Plūduma, L.; Veiderma, M. A review on the thermal stability of calcium apatites. J. Therm. Anal. Calorim. 2012, 110, 647-659. [CrossRef]

19. Liao, C.-J.; Lin, F.-H.; Chen, K.-S.; Sun, J.-S. Thermal decomposition and reconstitution of hydroxyapatite in air atmosphere. Biomaterials 1999, 20, 1807-1813. [CrossRef]

20. Tanaka, H.; Chikazawa, M.; Kandori, K.; Ishikawa, T. Influence of thermal treatment on the structure of calcium hydroxyapatite. Phys. Chem. Chem. Phys. 2000, 2, 2647-2650. [CrossRef]

21. Wang, T.; Dorner-Reisel, A. Thermo-analytical investigations of the decomposition of oxyhydroxyapatite. Mater. Lett. 2004, 58, 3025-3028. [CrossRef]

22. Drouet, C. A comprehensive guide to experimental and predicted thermodynamic properties of phosphate apatite minerals in view of applicative purposes. J. Chem. Thermodyn. 2015, 81, 143-159. [CrossRef]

23. Riboud, P.V. Comparaison de la stabilite de l'apatite d'oxyde de fer et de l'hydroxyapatite a haute temperature. Bull. Soc. Chim. Fr. 1968, 1701-1703.

24. Riboud, P.V. Composition et stabilité des phases à structure d'apatite dans le système $\mathrm{CaO}-\mathrm{P}_{2} \mathrm{O}_{5}$ - de fer- $\mathrm{H}_{2} \mathrm{O}$ à haute température. Ann. Chim. 1973, 8, 381-390.

25. Bhatnagar, V.M. The melting points of synthetic apatites. Miner. Mag. 1969, 37, 527-528. [CrossRef]

26. Ma, J.; Ge, X.; Pelate, N.; Lei, S. Numerical investigation of two-dimensional thermally assisted ductile regime milling of nanocrystalline hydroxyapatite bioceramic material. Ceram. Int. 2015, 41, 3409-3419. [CrossRef]

27. Bulina, N.V.; Baev, S.G.; Makarova, S.V.; Vorobyev, A.M.; Titkov, A.I.; Bessmeltsev, V.P.; Lyakhov, N.Z. Selective Laser Melting of Hydroxyapatite: Perspectives for 3D Printing of Bioresorbable Ceramic Implants. Materials 2021, 14, 5425. [CrossRef] [PubMed]

28. Bulina, N.V.; Rybin, D.K.; Makarova, S.V.; Dudina, D.V.; Batraev, I.S.; Utkin, A.V.; Prosanov, I.Y.; Khvostov, M.V.; Ulianitsky, V.Y. Detonation Spraying of Hydroxyapatite on a Titanium Alloy Implant. Materials 2021, 14, 4852. [CrossRef]

29. Trombe, J.; Montel, G. Some features of the incorporation of oxygen in different oxidation states in the apatitic lattice- - On the existence of calcium and strontium oxyapatites. J. Inorg. Nucl. Chem. 1978, 40, 15-21. [CrossRef] 
30. Bessmeltsev, V.P.; Goloshevsky, N.V.; Smirnov, K.K. Specific features of controlling laser systems for micromachining of moving carriers. Optoelectron. Instrum. Data Process. 2010, 46, 79-86. [CrossRef]

31. Raynaud, S.; Champion, E.; Bernache-Assollant, D.; Thomas, P. Calcium phosphate apatites with variable Ca/P atomic ratio I. Synthesis, characterisation and thermal stability of powders. Biomaterials 2002, 23, 1065-1072. [CrossRef]

32. Montel, G.; Bonel, G.; Heughebaert, J.; Trombe, J.; Rey, C. New concepts in the composition, crystallization and growth of the mineral component of calcified tissues. J. Cryst. Growth 1981, 53, 74-99. [CrossRef]

33. Dorozhkin, S. Solid-Phase Conversion of Nonstoichiometric Hydroxoapatite into Two-Phase Calcium Phosphate. Russ. J. Appl. Chem. 2002, 75, 1897-1902. [CrossRef]

34. Champion, E. Sintering of calcium phosphate bioceramics. Acta Biomater. 2013, 9, 5855-5875. [CrossRef]

35. Alberius-Henning, P.; Adolfsson, E.; Grins, J.; Fitch, A. Triclinic oxy-hydroxyapatite. J. Mater. Sci. 2001, 36, 663-668. [CrossRef]

36. Gross, K.; Berndt, C.; Stephens, P.; Dinnebier, R. Oxyapatite in hydroxyapatite coatings. J. Mater. Sci. 1998, 33, 3985-3991. [CrossRef]

37. Dorozhkin, S.V. Calcium orthophosphate deposits: Preparation, properties and biomedical applications. Mater. Sci. Eng. C 2015, 55, 272-326. [CrossRef] [PubMed] 